\title{
Early environment and behavioral-biochemical response to trifluoperazine in monkeys'
}

W. F. ANGERMEIER AND J. B. PHELPS, DEPARTMENT OF PSYCHOLOGY, FLORIDA PRESBYTERIAN COLLEGE, St. Petersburg, Fla. 33733, H. H. REYNOLDS, ARL, HOLLOMAN $A F B$, New Mexico, AND R. L. DAVIS, VA CENTER, Bay Pines

Twenty-four differentially reared male rhesus monkeys were used as $S s$ in this experiment. For 30 days the animals were injected twice daily with trifluoperazine. The effects of these injections were measured on a match-to-sample task previously learned and on a number of blood biochemical assessments. Results indicated that (1) the drug reduced the sensitivity to shock in a shock-escape match-to-sample task according to degrees of previous environmental stimulation during early rearing; (2) the least affected $S s$ were the animals reared in strict isolation, animals reared in partial isolation and under normal social conditions were moderately affected, and animals reared in enriched environments were greatly affected; (3) these effects could be interpreted to indicate differential early threshold development in the four rearing groups used in this experiment; and (4) drug injections could be considered "therapeutic" in the same sense that social change was thought to be therapeutic in a previous study.

There are a number of difficulties in measuring the effects of early isolation upon later learning ability. If the task to be learned is a difficult one, i.e., one requiring a large number of acquisition trials, the training procedures employed may serve to make experimental and control groups more alike and thus disguise possible existing differences. If the task to be learned is an easy one, differences may simply not appear at all. Published results on the learning ability of postisolates are at best inconclusive. Thompson \& Heron (1954), i.e., reported that isolated Scottish terriers performed poorer than controls on orientation and delayed-response tests, but Harlow (1967) and Angermeier, Phelps, \& Reynolds (1967) failed to find significant differences in rhesus monkeys reared differentially which were tested on a complex operant program. In one of the studies cited by Fuller (1967), dogs reared as pets and those reared in isolation were tested on a modified Wisconsin General Test Apparatus for spatial discrimination and reversal. Significant differences attributable to differential rearing were found only on one of 12 tests. One way in which previous experience effects have been tested has been the use of drugs, particularly the use of tranquilizers and so-called anti-anxiety drugs, such as chlorpromazine and trifluoperazine. In a study, using 16 dogs, Fuller (1967) showed that administration of chlorpromazine tended to have a suppressing effect upon emergence behavior into an observation arena. This effect, however, seemed to interact with previous handling, with the handled and drug-administered animals being the more nearly normal Ss. Animals which were administered the drug and were nonhandled rarely emerged into the arena from a transport cage and showed only $1 / 10$ to $1 / 20$ of the quantity of emergence

Table 1

Effects of Trifluoperazine upon Activity: Number of Trials Completed

\begin{tabular}{|c|c|c|c|c|c|c|}
\hline \multirow[b]{2}{*}{ Rearing Environments } & \multicolumn{2}{|c|}{ First 10 Days } & \multicolumn{2}{|c|}{ Second 10 Days } & \multicolumn{2}{|c|}{ Third 10 Days } \\
\hline & $\mathrm{s}^{\mathrm{a}}$ & $\mathrm{pb}^{\mathbf{b}}$ & $\mathbf{S}$ & $\mathbf{P}$ & $\mathrm{S}$ & $\mathbf{P}$ \\
\hline Strict Isolation & 304 & $500^{c}$ & 396 & 500 & 500 & 500 \\
\hline Partial Isoltaion & 153 & 500 & 270 & 500 & 106 & 500 \\
\hline Social & 208 & 500 & 112 & 500 & 99 & 500 \\
\hline Enriched Social & 88 & 500 & 11 & 500 & 51 & 500 \\
\hline
\end{tabular}

$a_{\text {Drug-injected (Stelazine) }}$

$b_{\text {Placebo-injected (Saline) }}$

$c_{\text {Maximum possible trials }}$
Table 2

Effect of Trifluoperazine on Number of Trials Completed

\begin{tabular}{lcc}
\multicolumn{1}{c}{ Groups } & Predrug/Drug & Drug/Postdrug \\
\hline Strict Isoltaion & .01 & .01 \\
Partial Isolation & .01 & .01 \\
Social & .01 & .01 \\
Enriched Social & .01 & .01 \\
\hline & & \\
& Difference Between & Group With \\
Groups Compared & Change: Predrug/Drug & Smaller Change \\
\hline \multicolumn{1}{c}{ SI-PI } & .01 & SI \\
SI-S & .01 & SI \\
SI-ES & .01 & SI \\
PI-S & N/S & PI \\
PI-ES & .01 & PI \\
S-ES & .02 & S \\
\hline
\end{tabular}

behavior shown by the other animals. In the study reported here, the effects of trifluoperazine upon match-to-sample behavior and blood biochemistry in male rhesus monkeys reared differentially were tested.

Subjects. Twenty-four male rhesus monkeys, approximately $20-22$ months of age at the beginning of the experiment were used as Ss. The animals were subdivided into four equal groups which corresponded to differential rearing conditions: (1) Strict Isolation Ss (SI): one animal per cage, no visual or tactual contact; (2) Partial Isolation Ss (PI): one animal per cage, visual and some tactual contact between cages; (3) Social Environment Ss (S): two animals per cage and visual and some tactual contact between cages; (4) Enriched Social Environment Ss (ES): two animals per cage, play objects, swings, colored rotating lights and an 8-h schedule of daily TV-watching. None of the animals were handled, except in the case of blood-withdrawal; neither had they been previously injected with any drug.

Apparatus. The apparatus for the match-to-sample task is described in detail elsewhere (Angermeier, Phelps, \& Reynolds, 1967). Briefly, it consisted of a stainless steel testing cage which permitted the presentation of various symbols for the match-to-sample task. Four symbols: $0, \square, \Delta,+$ were used in this study. The reinforcement used was shock-escape. All contingencies were automatically programmed.

Procedure. All of the Ss were trained to perform the match-to-sample task at asymptotic levels (less than $5 \%$ variation over 250 trials) during 50-trial sessions given every other day. Two animals from each rearing condition were then injected with trifluoperazine twice daily, at $7 \mathrm{AM}$ and at $7 \mathrm{PM}$, for 30 days $(.01 \mathrm{mg} / \mathrm{lb}$ body weight). Four animals from each rearing condition were injected with appropriate dosages of placebo. This procedure created the following subgroups: (1) a group which was injected with the drug and tested for match-to-sample performance; (2) a group not injected with the drug but tested for match-to-sample performance; and (3) a group not injected with the drug and not tested for match-to-sample performance (this latter subgroup was the control group for the biochemical assessments). Behavioral tests were thus available for a 10-day period preceding drug injections, a 30-day period during drug-injections, and a 10-day period following drug injections. Fasting blood samples ( $34 \mathrm{cc}$ from the great saphenous vein) were taken 3 days prior to drug injections, and on days 3,13 , and 23 during the drug injection period. The blood plasma samples were analyzed by standard techniques for Cholinesterase, Calcium, Tyrosine, Cholesterol, Total Protein, and Glutamic Oxalacetic Transaminase (SGOT).

Results. Since most of the drug-injected animals did not complete any or all of their daily trials during the 30-day drug-injection period, the only useful raw data to be analyzed were the number of trials completed during this period. For this analysis, the sums of 10-day periods were used as the basic unit of analyses. Sessions were terminated when $\mathrm{S}$ failed to respond to 
Table 3

Trifluoperazine and Optimal Improvement in Biochemical Assessments

\begin{tabular}{lcc}
\multicolumn{1}{c}{ Measure } & Improvement & $\mathrm{p}$ \\
\hline Cholinesterase & Yes & $\mathrm{N} / \mathrm{S}$ \\
Calcium & Yes & $\mathrm{N} / \mathrm{S}$ \\
Tyrosine & Yes & .01 \\
Cholesterol & Yes & $\mathrm{N} / \mathrm{S}$ \\
Total Protein & Yes & .01 \\
SGOT & Yes & .01 \\
\hline
\end{tabular}

one presentation within $200 \mathrm{sec}$. The raw data are shown in Table 1. It is evident from Table 1 that the SI animals were the least affected, the PI and S animals were moderately affected, and the ES animals were the most thoroughly affected animals by the drug injections. An analysis of significant differences between predrug and drug periods and drug and postdrug periods is shown in Table 2. It is clearly evident that the drug injections significantly affected the number of trials which animals were able to complete during their 50-trial sessions. All predrug and drug, and drug and postdrug comparisons showed significant differences ( $p$ $<.01$ ). When individual rearing groups were compared with each other, it was evident that all groups differed significantly from each other as far as severity of reaction to the drug was concerned, except for the PI and S animals. The effects of the drug on optimal improvement in biochemical measures from predrug to drug period were analyzed by the appropriate $t$ tests. The results of that analysis can be seen in Table 3. All measures showed improvement, with Tyrosine, Total Protein, and SGOT showing significant improvements.

Discussion. The data presented here seem to indicate that animals reared in sensory-social isolation become adapted to a very low average level of stimulation; the opposite is true of animals reared in enriched social environments. When the drug was administered, trifluoperazine effectively raised the existing thresholds. This fact resulted in the ES animals reaching a level of functioning where they did not perceive or did not react to the stimulation presented by the shock-escape match-to-sample task. The other rearing subgroups seem to have fallen in line proportionately to the sensory input which they experienced during their early rearing environments. Since the SI animals were at the very lower end of the threshold range, the drug raised their threshold but their functioning remained within the effective range of reaction to stimulation. This is the reason why these animals showed little or no measurable response to the drug. The explanation offered here is in accord with Fuller's theory (1967) of the stress of emergence phenomenon observed in dogs, which seems to account adequately also for the observations made in this study. Finally, it was interesting to ascertain that trifluoperazine significantly affected the biochemical values assessed here much in the same way in which they were affected in a previous study by a change of social environment. Since the real differences between our rearing groups existed within the realm of social deprivation rather than in the area of perceptual isolation, it is suggested by the data that the social components of the early rearing environment are more important determinants of attained stimulation levels than the perceptual components. Further study in this area should be directed toward a more distinct delineation of these variables.

\section{REFERENCES}

ANGERMEIER, W. F., PHELPS, J. B., \& REYNOLDS, H. H. The effects of differential early rearing upon discrimination learning in monkeys. Psychon. Sci, 1967, 8, 379-380.

FULLER, J. L. Experimental deprivation and later behavior. Science, 1967, $158,1645-1652$.

HARLOW, H. F. Personal communication. In Fuller, J. L. Experimental deprivation and later behavior. Science, 1967, 158, 1645-1652.

THOMPSON, W. R., \& HERON, W. The effects of early restriction on activity in dogs. J. comp. physiol. Psychol., 1954, 47, 77-82.

\section{NOTES}

1. This research was sponsored by AF Contract AF29600-67-C-0011 between Aeromedical Research Laboratory, Holloman AFB, New Mexico and Florida Presbyterian College.

2. A more detailed report is available upon request.

3. Appreciation is expressed to Smith, Kline and French Laboratories, Philadelphia, Pennsylvania, for making Stelazine (trifluoperazine) available to this study without charge. 